\title{
An examination of the differential susceptibility pattern of the dentition to linear enamel hypoplasia
}

\author{
by Jennifer S. Nelson
}

Enamel hypoplasia is a dental pathology that forms when an individual is exposed to physiological stress in early life while tooth crowns are developing. Biological anthropologists utilize these enamel defects as indicators of growth interruption and interpret them as reflective of factors pertaining to health status and cultural practices that influence health. Over decades of research, numerous studies have noted a pattern in the distribution of linear enamel hypoplasia across the dentition. It is suggested that the anterior dentition presents the highest frequency of defects, followed by the premolars, with molars most rarely exhibiting hypoplasia. This apparent differential susceptibility pattern has resulted in the preferential study of the anterior dentition in anthropology, however little research has been conducted into the validity or cause of this developmental phenomenon. Through examination of the literature, the observed higher frequency of enamel hypoplasia in the anterior dentition substantiates the existence of this differential distribution pattern. Further investigation reveals that the cause of this varying susceptibility has not been sufficiently explored, leading to a number of inconclusive explanations. Examination of these theories - ranging from the chronology of tooth development, specifics of crown morphology, and variations in genetic control - indicate that there is no single causal variable, but that a multitude of factors are responsible. From this research it is apparent that further study is necessary to fully understand why the anterior teeth appear to be more susceptible to hypoplastic defects than their posterior counterparts.

\section{Introduction}

Enamel hypoplasia is a highly studied type of dental pathology that forms when an individual is exposed to physiological stress in early life while tooth crowns are developing. Unlike bones, that undergo constant remodelling thereby removing any evidence of growth disruption, enamel is an acellular tissue that provides a relatively permanent record of an individual's past health. Although several different types of hypoplasia exist, the focus of this paper is on the most commonly studied: the linear variety. In the

Jennifer S. Nelson is a Doctoral student at the University of Alberta (Department of Anthropology (13-15 HM Tory Building, Edmonton, Alberta, T6G 2H4 [jsnelson@ualberta.ca]). examination of various populations, researchers have noticed a pattern in the distribution of linear enamel hypoplasia across the dentition. Many articles note that the anterior dentition presents the highest frequency of defects, followed by the premolars, with molars more rarely exhibiting linear hypoplasia (Goodman and Armelagos 1985a; Goodman and Rose 1990; Hutchinson and Larsen 1988; Moggi-Cecchi et al. 1994; Wood 1996). Based on the differential distribution of enamel defects, it has been suggested that the teeth of the anterior dentition - incisors and canines - are more susceptible to linear hypoplasia than the posterior premolars and molars.

The differential susceptibility to enamel defects is an important area of study for 
biological anthropologists, as it may lead to the preferential study of just the anterior dentition. For example, during data collection, researchers will sometimes choose to not examine the posterior teeth in a collection, often due to limitations of time and budget (Wood 1996; Goodman and Armelagos 1985b; Zhou and Corruccini 1998; Blakey, Leslie and Reidy 1994. This is based on the idea that premolars and molar are less affected by enamel hypoplasia and are therefore less indicative of the health of the population. If this assessment is correct, the practice of preferential observation is justified, saving time by not examining less informative teeth. However, if this habit has merely been accepted over the years, potentially valuable information from the posterior teeth may be lost or overlooked. The intent of this paper is threefold; first, to review the existing literature on the frequency and aetiology of linear enamel hypoplasia (LEH), second, to assess if this distribution pattern is found consistently across populations, and third, to explore the various theories for this differential susceptibility and critically evaluate their validity. It is hypothesized that an examination of the numerous theories that currently exist regarding this pattern will conclude that the phenomenon is the result of multiple factors, and that no single theory adequately explains all elements of LEH susceptibility.

If this differential susceptibility pattern is valid, it is not enough to simply acknowledge its existence. It is important for biological anthropologists to understand why this pattern occurs, as it aids in our overall knowledge behind the formation of hypoplasia. This in turn furthers our comprehension of what these defects can tell us about the overall health of past populations. The existing literature will be examined in an attempt to determine if this pattern of varied susceptibility is consistent, and if so proven, explore the proposed supporting theories and critically assess their explanations. A brief description of tooth crown development and timing is included, as a basic understanding of normal enamel formation is fundamental to comprehending disruptions in the process. For ease of understanding, potential hypotheses have been organized into one of three subcategories based on the nature of their argument: chronology, crown morphology, and genetic control.

\section{Normal Dental Development}

\section{Initial Formation}

Based on the length and scope of this paper, only a brief description of the complex process that is dental development will be explored. This discussion will not include the final stages of eruption and root completion, as they are not pertinent to the topic of LEH. For a more in-depth explanation of tooth formation and development, the following sources are recommended: Hillson 2014; Scheuer and Black 2004; Lesot and Brook 2009. Initial formation of the oral cavity begins around 4 weeks in utero, with dental development beginning shortly thereafter (Hillson 2014). The dental lamina appears at approximately 6 weeks gestational age, where portions of epithelium begin to thicken and penetrate into its underlying mesenchyme, creating tooth germs (Hillson 2014). Numbering ten in total, each of these germs will form into a deciduous tooth bud, with the tooth germs for the permanent dentition appearing at roughly the $16^{\text {th }}$ week in utero (Lesot and Brook 2009). These buds will form the enamel organ, while condensed mesenchymal tissue will create the dental papilla, marking the end of what is known as the "bud stage" (Lest and Brook 2009). 


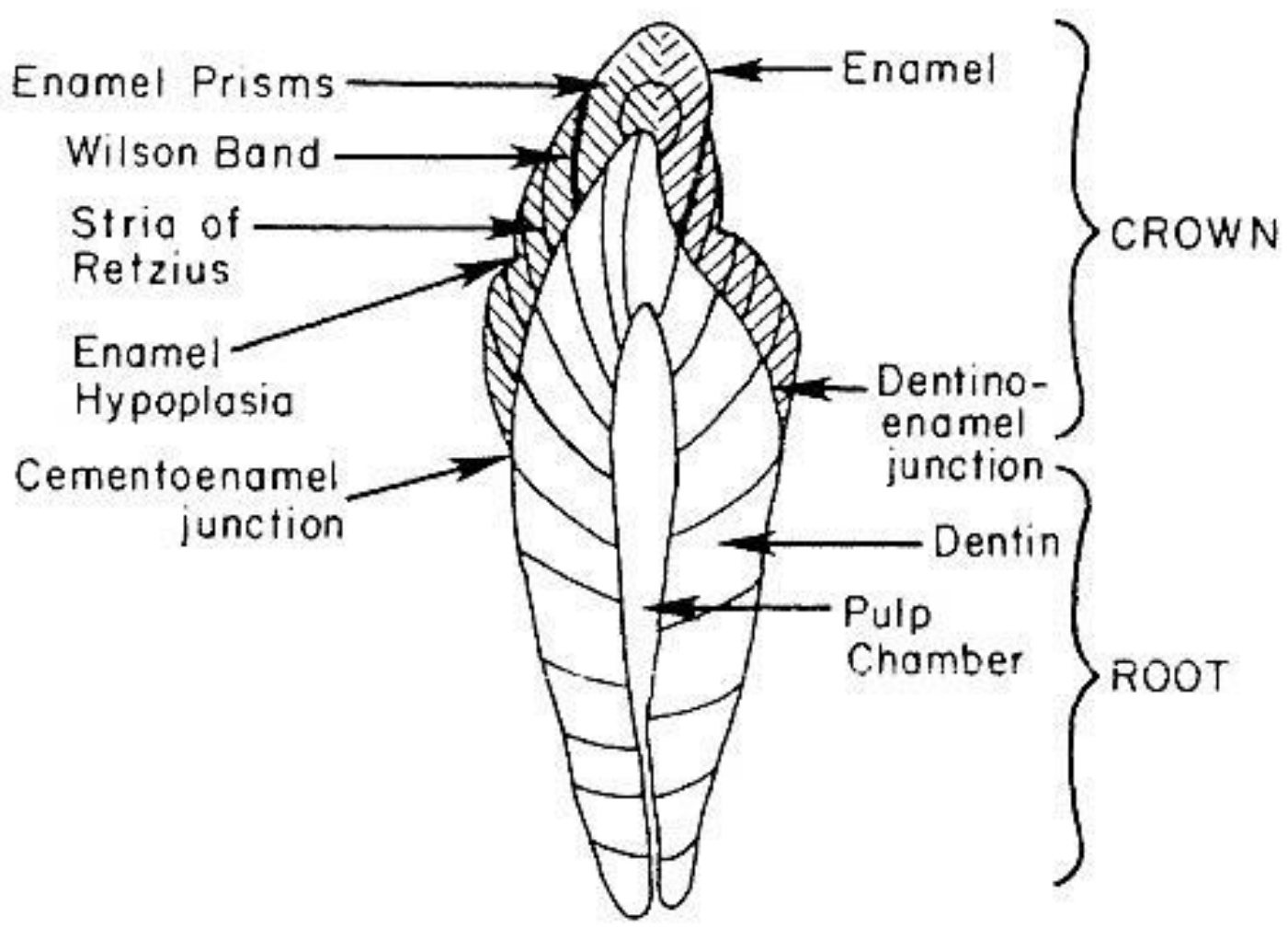

Figure 1. A depiction of how the enamel prisms and striae of Retzius form the enamel layer of the tooth crown, including representations of enamel hypoplasia (Goodman and Rose 1990:62).

The subsequent stage of tooth development or cap stage - commences when the enamel organ begins to wrap around the dental papilla, creating a cap-like structure (Scheuer and Black 2004). A thin layer of mesenchyme, known as the dental follicle, then surrounds the outer aspect of the enamel organ (Scheuer and Black 2004). Eventually the cupped shape of the enamel organ deepens, marking the beginning of the third and final stage of development: the bell stage (Hillson 1996). It is during this stage that the shape of the future cusps and tooth crown begin to form at the contact zone of the dental papilla and enamel organ (Hillson 1996). It is also here that cells begin to differentiate late in the bell stage, with the cells of the dental papilla giving rise to dentine-secreting odontoblasts, while enamel organ cells will become enamel-forming ameloblasts (Scheuer and Black 2004).

\section{Enamel Formation}

Ameloblasts are of key importance to this paper, as disruptions during the secretory phase of their activity are what ultimately cause the formation of LEH. Beginning at the contact zone between the papilla and enamel organ - also known as the dentino-enamel junction or DEJ - ameloblasts begin to secrete enamel matrix, which is deposited in layers down the crown from the tip of each cusp, as represented in Figure 1 (Lesot and Brook 2009). This matrix is composed of protein, water, and calcium phosphate in the form of hydroxyapatite (HA) crystals (Oliveira et al. 2010). HA crystals do not undergo continuous 
growth but grow incrementally (Oliveira et al. 2010). These increments are the daily HA crystal elongation, appearing as prism cross-striations that run approximately perpendicular with the crown surface (Simmer and $\mathrm{Hu} 2001$ ). Every 7 to11 days, more prominent cross-striations are formed, known as striae of Retzius (Hillson 1996). When these striae reach the enamel surface of the crown, they are referred to as perikymata (Hillson 1996). These layers of soft, protein-rich matrix increase in thickness, becoming progressively more steep and narrow as they reach the cervical edge of the crown (Bartlett 2013).

Ameloblasts stop producing enamel matrix once the cemento-enamel junction (CEJ) has been reached, after which crown mineralization begins (Scheuer and Black 2004). Following the secretory phase, ameloblast functionality switches from enamel production to mineralization (Goodman and Rose 1990). This process begins at the cusp tips or incisal edge, spreading downward until the crown is complete (Liversidge and Molleson 1999). After transporting and absorbing the protein and water components of the enamel matrix, the ameloblasts expand and die, leaving an acellular inorganic tissue that is incapable of remodelling (Goodman and Rose 1990).

\section{Developmental Chronology}

It is around 2 to 4 months postnatal that the first of the deciduous teeth - the first and second incisors - complete their crown development (Sunderland et al. 1987). At approximately 6 months the third premolar achieves crown completion, followed shortly by the canine at roughly 8 to 10 months of age. The last of the deciduous teeth to complete its crown formation is the fourth premolar, which occurs by around the tenth or twelfth month postnatal (Sunderland et al. 1987).

In comparison to the deciduous dentition, which undergoes most of its development in utero, the permanent teeth do not start developing until after the child is born. The crowns of the permanent incisors (first and second), canines, and first molars have all begun their development by the end of the first year of life (Massler and Schour 1946). The first molars begin their initial crown formation around the time of birth, completing their crowns at approximately 2 to 4 years of age (Gustafson and Koch 1974). All anterior teeth - excluding the upper second incisors - have begun crown formation by the 2 to 4 month mark after birth (Liversidge 2000). It is not until around the tenth month of life that the upper second incisors will begin their crown development (Liversidge 2000). Although their crowns begin formation at roughly the same time, all incisor crowns are complete by approximately 3 to 5 years of age, while the crowns of the canines are not fully formed until around the 4 to 7 year mark (Gustafson and Koch 1974). The premolars and second molar begin their crown development roughly 2 to 4 years after birth, achieving full crown completion at approximately 6 to 8 years of age (Massler and Schour 1946). The third molar is the last of the dentition to undergo crown formation, beginning at around 7 to 9 years of age and not achieving full crown formation until early adolescence, although these ranges are incredibly variable (Massler and Schour 1946).

\section{Hypoplastic Enamel Development}

Enamel hypoplasia is a deficiency in the enamel thickness of tooth crowns, caused by a disturbance in ameloblast activity during the secretory or matrix formation stage of 


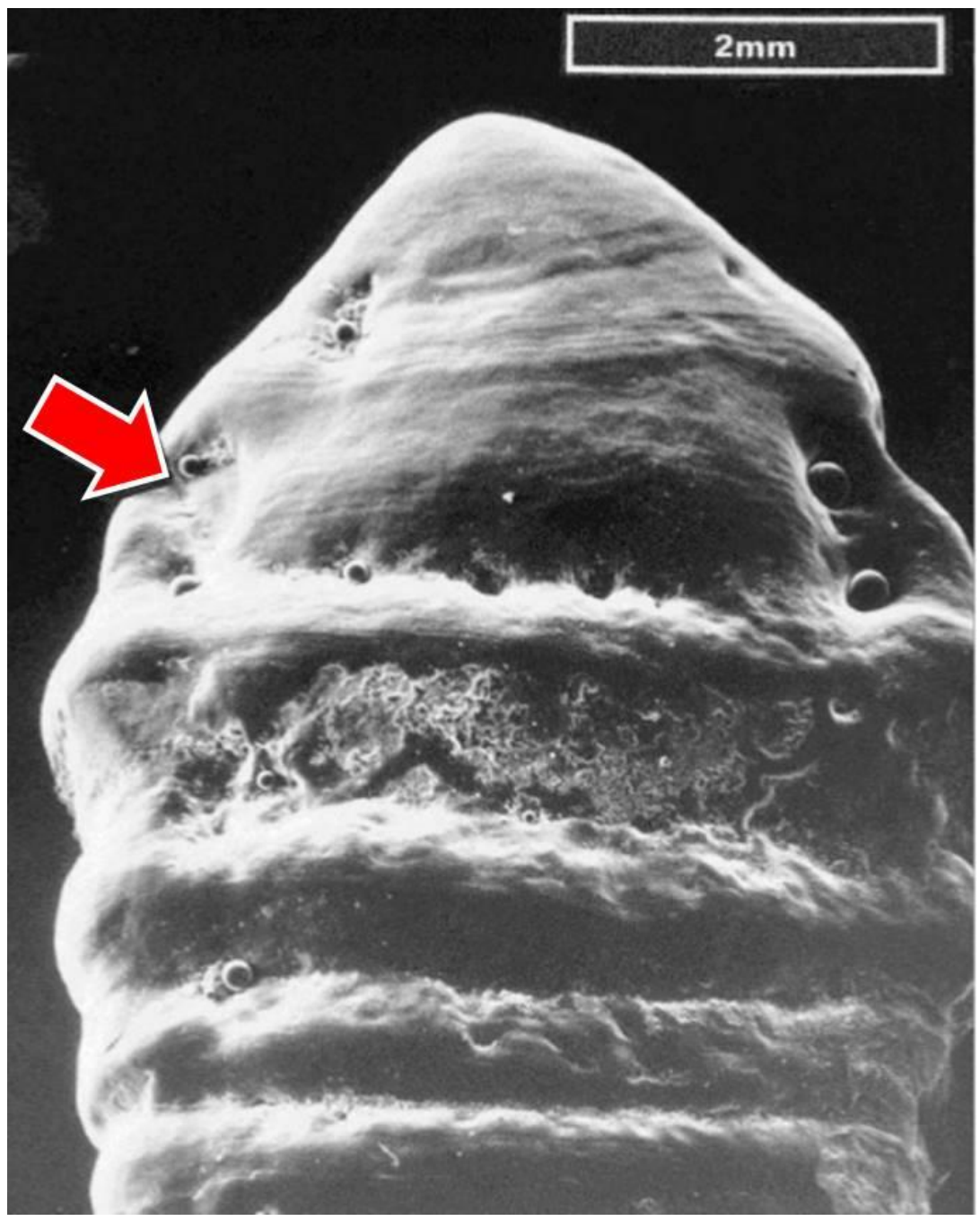

Figure 2. An example of a lower right canine, exhibiting all three types of defects. On the upper third of the crown there are linear defects visible, along with associated pits of varying sizes (the red arrow indicates one of these pit-form defects). The lower half of the tooth crown shows major plane form defects, appearing as "steps" (Hillson and Bond 1997:90).

amelogenesis (Goodman and Armelagos 1985). Hypoplastic defects are known to result from hereditary conditions, poor nutrition, disease, and localized trauma (Hillson 1979). These enamel defects can appear as one of three types: pit, plane, or furrow (see Figure 2). The aetiology of the pit and plane forms is not fully understood; however, they are believed to be the result of trauma or infection in the area near the tooth (Hillson 1979). Hypoplasia resulting from a hereditary condition is easily identifiable, as the whole tooth crown or entire dentition will typically be affected (Goodman and Rose 1990). These are quite rare, with a prevalence rate of less than $1 \%$ in modern populations, and typically caused by amelogenesis imperfecta (Goodman and Rose 1990). In comparison, hypoplastic defects caused by localized trauma or infection will generally appear on only one or two adjacent teeth (Goodman and Armelagos 1985a). 


\section{Linear Enamel Hypoplasia (LEH)}

The most common and well-understood hypoplasia type is the furrow or linear defect (Hillson and Bond 1997). These are believed to be caused by periods of non-specific stress and are generally observable on most or all of the dentition developing at that time (Goodman and Rose 1990). In this context, the term stress can include any physical disruption in response to changes in an individual's environment or psychological state (Hillson 2014). If an individual is exposed to a stressor at an age when their tooth crowns are being formed, their stress response system signals ameloblasts to slow their secretion of enamel (Kumar 2011). If the stress continues, enamel secretion halts entirely, resuming only once the period of stress has ended (Ritzman et al. 2008).

While the precise source of the stress - i.e. malnutrition versus disease - cannot be determined from the hypoplasia, it is possible to estimate the approximate age of occurrence and duration of the incident. By comparing the location of the defect on the tooth crown to established formation charts, an age can be estimated. This can often be substantiated by examining the enamel of other teeth known to develop at that time to check for "matched" defects (Hillson and Bond 1997). It is possible to approximate the length of the stress episode by counting the number of perikymata grooves in the occlusal wall of the defect (Hillson and Bond 1997). By following the general rule that a single perikymata is laid down every 7 to 11 days, calculations can then be made that provide an estimate of duration (Reid and Ferrell 2006).

The study of enamel defects is important because of the information they can provide regarding the health of an individual and, when examined as part of a larger skeletal sample, the overall health of a population. For instance, there are many articles that focus on the health effects of weaning processes in various cultures (Blakey, Leslie and Reidy 1994; Corruccini, Handler and Jacobi 1985; Moggi-Cecchi et al. 1994). Other research has compared the frequency of LEH in male and female children in an attempt to identify indications of preferential treatment based on sex (King, Humphrey and Hillson 2005; LiebeHarkort 2010; Palubeckaite, Jankauskas and Boldsen 2002). The same has been done in individuals of varying socioeconomic classes, with the purpose of increasing our understanding of how factors related to an individual's socioeconomic background might affect their dental health.

\section{Deciduous Dentition}

While numerous articles exist on hypoplastic defects in the enamel of the deciduous dentition, these are rarely specific to the linear form or do not specify what type of defects are being observed (Duray 1990; Aminabadi et al. 2009; Blakey, Leslie and Reidy 1994; Blakey and Armelagos 1985; Sciulli 1977; Lunardelli and Peres 2005). The research on general hypoplasia in deciduous teeth has found that, while they have a lower frequency of defects than their permanent counterparts, they are still affected by hypoplasia of all types (Infante and Gillespie 1974; Jelliffe and Jelliffe 1971; Sweeney et al. 1969). This differential susceptibility could be due to the more favourable and sheltered nature of the fetal environment during initial formation of these teeth, or a potentially higher resistance to enamel hypoplasia (Goodman and Rose 1990). It could also be a product of the different enamel that forms deciduous tooth crowns, which is thinner and less mineralized than that of the permanent dentition, in addition to having a thicker and more uniform layer of prismless enamel at the crown surface (Oliveira et al. 2010). Until more research 
Table 1 Frequency of linear enamel hypoplasia in the anterior compared to the posterior dentition based on study conducted during literature review

\begin{tabular}{|c|c|c|c|}
\hline Study & Anterior & Posterior & Notes \\
\hline Cucina 2002 & $67.1 \%$ & $34.9 \%$ & Population 1 \\
\hline Cucina 2002 & $82.3 \%$ & $45.2 \%$ & Population 2 \\
\hline Cucina 2002 & $81.6 \%$ & $61.0 \%$ & Population 3 \\
\hline $\begin{array}{l}\text { Hutchinson and } \\
\text { Larsen } 1988\end{array}$ & $86.0 \%$ & $45.0 \%$ & $\begin{array}{l}\text { Population 1. Rough percentages estimated } \\
\text { from graph. }\end{array}$ \\
\hline $\begin{array}{l}\text { Hutchinson and } \\
\text { Larsen } 1988\end{array}$ & $75.2 \%$ & $49.0 \%$ & $\begin{array}{l}\text { Population } 2 . \text { Rough percentages estimated } \\
\text { from graph. }\end{array}$ \\
\hline King et al. 2005 & $\begin{array}{l}\text { higher } \\
\text { frequency }\end{array}$ & $\begin{array}{l}\text { lower } \\
\text { frequency }\end{array}$ & $\begin{array}{l}\text { No raw numbers or percentages given per } \\
\text { tooth type. }\end{array}$ \\
\hline $\begin{array}{l}\text { Cucina and Iscan } \\
1997\end{array}$ & $87.3 \%$ & $50.6 \%$ & \\
\hline $\begin{array}{l}\text { Moggi-Cecchi et al. } \\
1994\end{array}$ & $70.1 \%$ & $57.5 \%$ & $\begin{array}{l}\text { Only M1 was examined from posterior } \\
\text { dentition. }\end{array}$ \\
\hline Liebe-Harkort 2012 & $\begin{array}{l}\text { higher } \\
\text { frequency }\end{array}$ & $\begin{array}{l}\text { lower } \\
\text { frequency }\end{array}$ & $\begin{array}{l}\text { No raw numbers or percentages given per } \\
\text { tooth type, } 77.8 \% \text { of affected teeth were } \\
\text { anterior. }\end{array}$ \\
\hline El Najjar et al. 1978 & $67.0 \%$ & $28.8 \%$ & Does not include third molars. \\
\hline Yamamoto 1988 & $48.5 \%$ & $22.0 \%$ & Does not include third molars. \\
\hline $\begin{array}{l}\text { Goodman and } \\
\text { Armelagos } 1985 b\end{array}$ & $42.9 \%$ & $17.0 \%$ & Does not include third molars. \\
\hline Ogilvie et al. 1989 & $41.0 \%$ & $15.9 \%$ & Does not include third molars. \\
\hline Stodder 1997 & $33.3 \%$ & $6.1 \%$ & \\
\hline $\begin{array}{l}\text { Krenz-Niedbala and } \\
\text { Kozlowski } 2013\end{array}$ & $\begin{array}{l}\text { higher } \\
\text { frequency }\end{array}$ & $\begin{array}{l}\text { lower } \\
\text { frequency }\end{array}$ & $\begin{array}{l}\text { No raw numbers or percentages given per } \\
\text { tooth type, does not include the molars. }\end{array}$ \\
\hline
\end{tabular}

is done on the frequency of LEH in deciduous dentition, little can be concluded about their aetiology or prevalence.

\section{Literature Review}

A selective review of the literature was performed to ascertain if the differential susceptibility pattern previously described in this paper is indeed observed in the literature, or if it is unsubstantiated by existing research. In order to carry out this review, a search of the University of Alberta's library system was completed using the search strategy: linear enamel hypoplasia and anterior and posterior and frequency. Only peer- reviewed articles from accredited sources were reviewed to maintain the credibility and trustworthiness of these results. The search did not limit the time frames of the articles as the author prioritized the inclusion of the first search results, as those are the publications which a reader would most commonly come across. The review, which is recorded in Table 1, considered the frequency of linear enamel hypoplasia in the anterior vs. the posterior dentition. If the study did not include any of the posterior teeth, the study was not included. Where the frequencies of the individual tooth types were reported as raw percentages, the data was combined to determine the comparative frequency. 
While this review aims to provide an unbiased overview of the literature, the possibility of some biases does remain. For instance, the previously mentioned preferential reporting of only the anterior dentition has resulted in a limited number of publications where a comparison between the two tooth categories is possible. As such, the review exhibits some repetition in authors who employ more exhaustive reporting methods when studying linear enamel hypoplasia. Although this is a potential bias, it is one that is inherently tied to the overall purpose of this paper - the exploration of the differential susceptibility of the dentition to enamel defects and the resulting preferential study of anterior teeth. For this reason, it was deemed necessary to include these studies in spite the risk of bias. Another potential source of bias lies in the methods used by the authors to measure the presence of LEH, however this is not believed to be an issue when comparing their reported frequencies. While there may be slight variations between studies, as the same methods were used when assessing the anterior and posterior dentition within each study, variation in the methods between studies should not be a source of bias or error save for the exclusion of the second and/or third molars by some studies, which has been noted in the table.

A total of 15 archaeological case studies were gathered, all of which found higher frequency of LEH in the incisors and canines than in the posterior teeth (table 1). These articles are by no means an exhaustive literature review of the frequency distribution of LEH but were included in an effort to quickly establish if the differential distribution pattern of higher frequency in the anterior dentition held true in the research. From this very brief review of the literature, the differential susceptibility pattern for greater frequency of LEH in the anterior dentition does appear to exist across various studies. Of the 15 articles collected, none found a higher or equal frequency of enamel defects between the teeth of the posterior and anterior dentition. Following the results of this review, it can be concluded that the presence of this pattern requires further exploration of the various theories explaining the phenomenon.

\section{Chronology}

\section{Time of Development}

The "time of development" hypothesis is one of the more popular explanations for hypoplastic distribution, due to its logic and simplicity (Goodman and Armelagos 1985a). This theory is based on the premise that teeth developing at ages when periods of stress are most common have a higher potential for hypoplastic defects (Hillson 1979). Studies have found that the period of childhood between approximately 6 months to 5 years has the highest incidence of general stress episodes, although this is population specific and as such is quite variable (Ubelaker 1989). In some instances, anthropologists are able to substantiate these chronological distributions by examining written records to gain insight into a population's cultural practices and history of disease. For example, the period of weaning is known to cause stress responses in the enamel of children, potentially because of the physiological reaction to the reduction of nutrients or the psychological effect of less motherly interaction (Blakey et al. 1994). While these periods are culturally specific, there is a fair amount of overlap between cultures that might explain the higher frequency of hypoplasia in certain teeth. By examining dental age development charts, it can be established that the incisors and canines are undergoing crown development during these ages (approximately 6 months to 5 years), which would explain why 


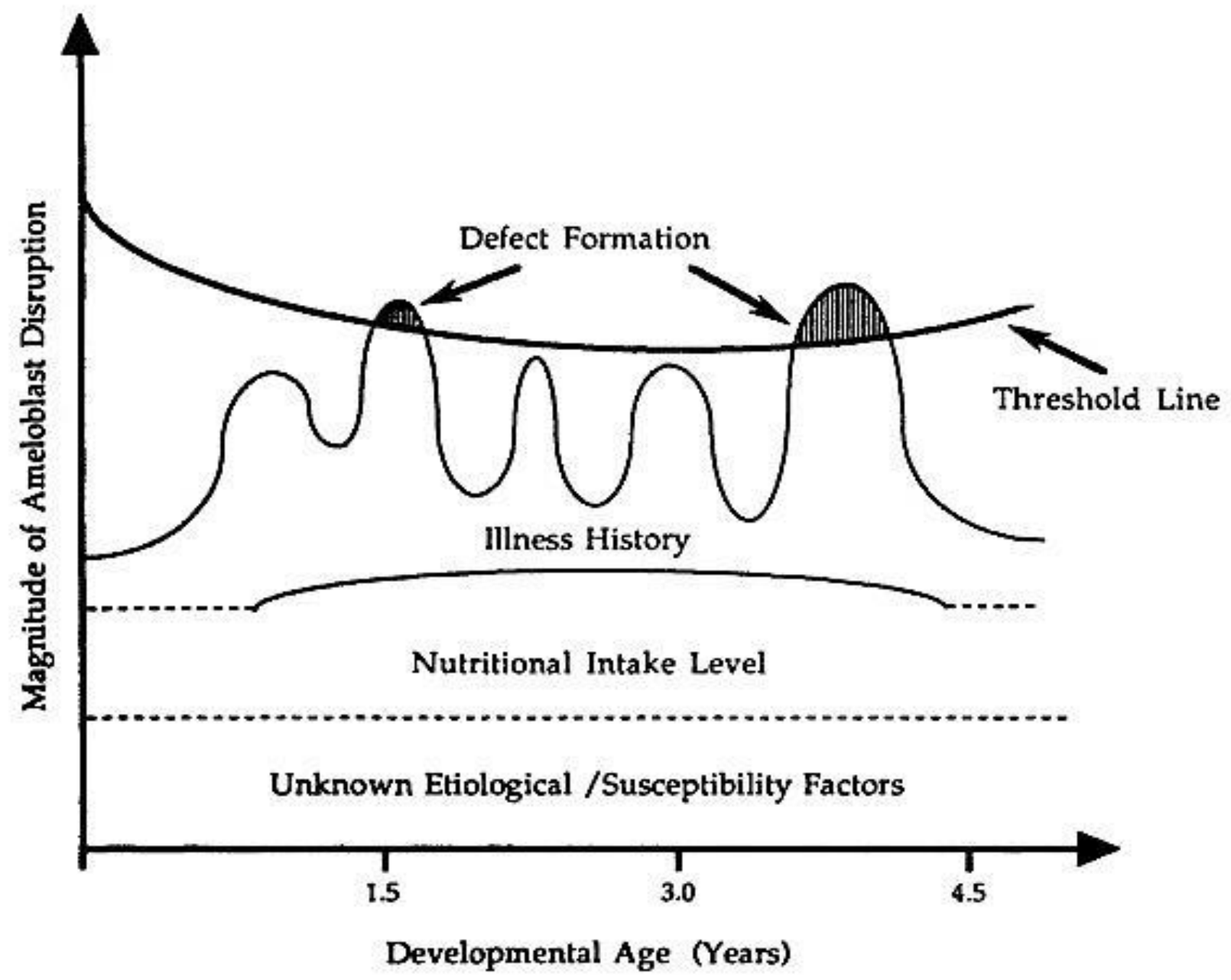

Figure 3. If the theory of younger children having poorer immune systems is correct, the theoretical threshold line depicted above would be lower relative to individuals later in childhood (Goodman and Rose 1990:75).

incisor and canine tooth types generally have a higher frequency of LEH (Schour and Massler 1941). However, it does not justify why the permanent first molars, which are also developing during this period, are rarely found with enamel defects (Schour and Massler 1941).

\section{Immune System}

Some authors suggest that the higher frequency of LEH in the enamel of teeth developing at this time should not be attributed to a single stressor or factor, but to the generally poorer immune system of young children (Witzel et al. 2008). This difference is argued to result in a lower stress threshold in children than older individuals, causing more dramatic hypoplastic responses to less severe stressors (Witzel et al. 2008). Figure 3 shows a theoretical model of how the relationship between an individual's threshold level and the magnitude of a stressor determine the formation of enamel defects. While this might explain why the second and third permanent molars very 
rarely present with hypoplasia, it still fails to explain the lack of enamel defects observed on the first permanent molars, which as stated previously, also develop during this time.

\section{Summary}

While there is evidence that the age at which a tooth's crown develops is a major factor in its frequency of linear hypoplasia, it cannot be the only one. It has been pointed out by some authors that teeth with simultaneously forming enamel do not exhibit hypoplastic defects to the same extent (Condon 1981; Goodman and Armelagos 1985a; King et al. 2005). This is supported by the observation of matched enamel defects, which in spite of being caused by the same growth disruption, can vary in their size and prominence (Hillson and Bond 1997). This is a phenomenon that is not unique to comparisons of anterior versus posterior dentition. For example, in their 1985 study, Goodman and Armelagos found that the incisor is 1.36 times as susceptible to hypoplastic defects as the canine when observing enamel development between the ages of 0.5 to 4.5 years (Goodman and Armelagos 1985a). Additionally, amongst the incisors, the maxillary central incisor was found to be 1.7 times more susceptible to enamel defects between 1 and 4 years of age (Goodman and Armelagos 1985a). From this information it can be inferred that other factors must be involved in the development of linear enamel hypoplasia, whether they be the differential reactivity of enamel at different regions of the crown to stress, or perhaps a variable more specific to tooth type.

\section{Crown Morphology}

\section{Rate of Growth}

In addition to the age that a tooth undergoes development, it has been suggested that the geometric morphology of its crown also has an important role in its susceptibility to LEH. Several studies have observed that tooth crown zones formed earlier in development typically have fewer hypoplastic defects than those forming later on. One possible explanation for this is that their faster growth rate and shorter development period result in lower potential for a stress episode to occur (Hillson 1979). While this is a logical theory, others have found disagreeing results. Goodman and Armelagos (1985a) have reasoned that because the ameloblasts in these crown regions secrete more enamel in a given amount of time, disturbances to their activity are more severe. For teeth such as the incisors, which grow at a relatively fast rate of $2.20-2.54 \mathrm{~mm}$ per year, this theory might explain their higher frequency of hypoplasia (Goodman and Armelagos 1985a). However, as with the age of development theory, this argument cannot fully explain the apparent differential susceptibility to enamel defects. For instance, while the canines are among the slowest growing teeth (1.65-1.75 $\mathrm{mm}$ per year), they are also among those teeth affected by hypoplasia at the highest frequency (Goodman and Armelagos 1985a). It is possible that both theories are correct in their own right, but that other factors are involved in the final expression of enamel hypoplasia on the various tooth crowns.

\section{Perikymata Spacing and Ameloblast Lifestyle}

Enamel defects tend to be more common in the mid-crown and cervical region of teeth, often attributed to the reduced spacing between perikymata near the crown cervix which causes defects here to be more apparent (Goodman and Rose 1990; King et al. 2005). This distribution is consistent across all tooth types, indicating that crown morphology is a definite factor in hypoplastic defect formation and is independent 
Total count 168 brown striae of Retzius

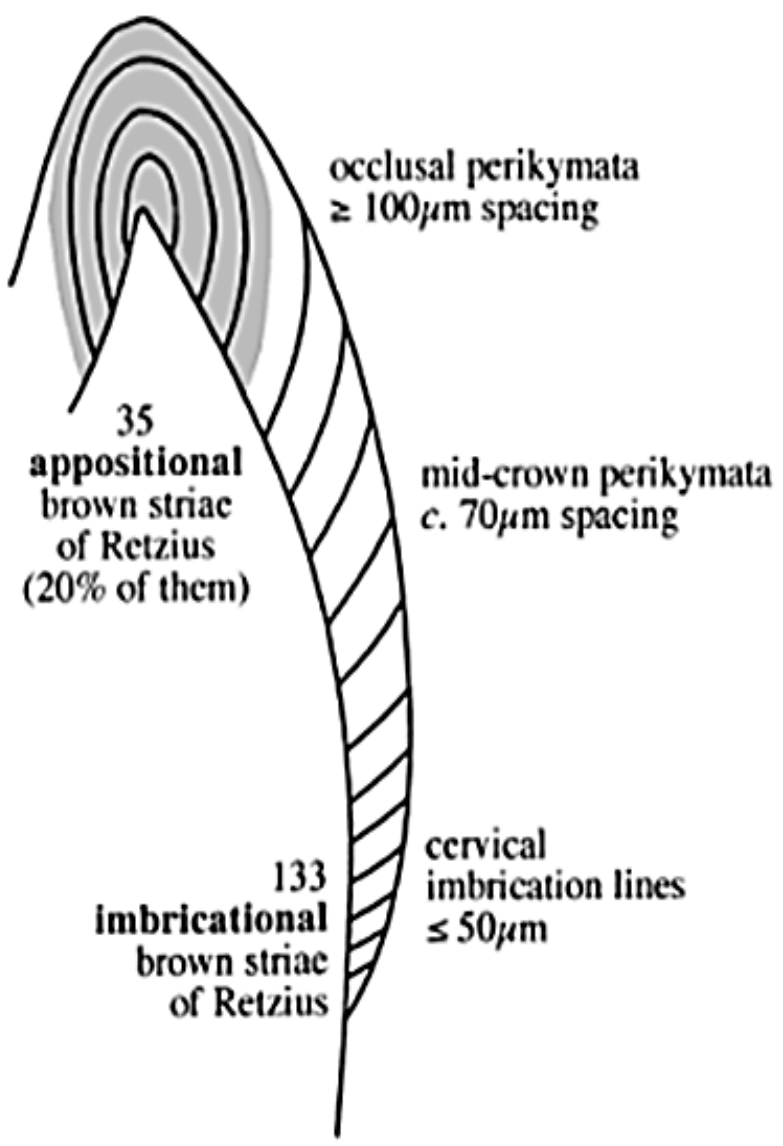

Total count 160 brown striae of Retrius

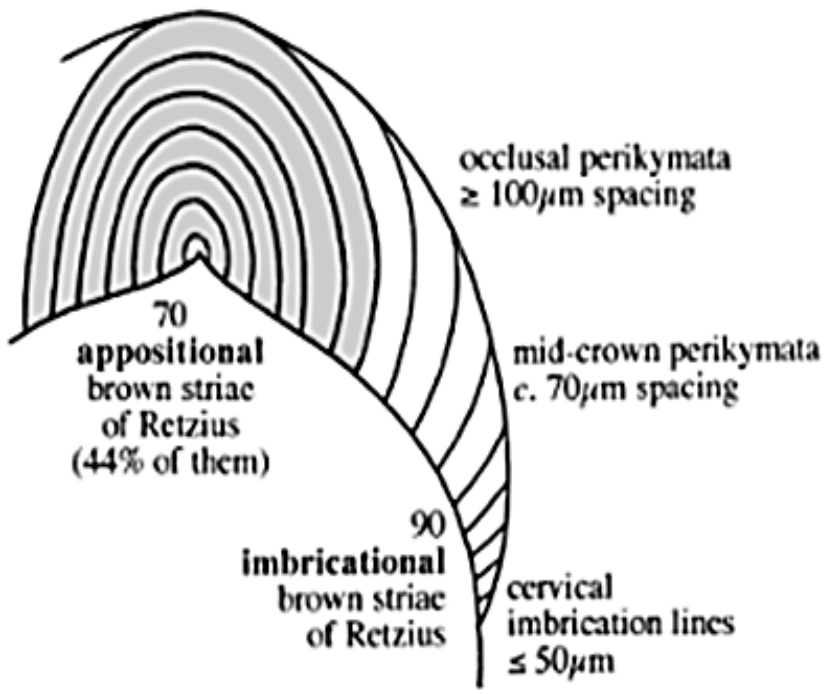

lines drawn every 10th brown stria

\section{lines drawn every 10th brown stria}

Figure 4. Representations of crown growth depicting the difference in appositional enamel present in incisor (A) and molar crowns (B) (Hillson and Bond 1997:90).

of the time of development (Goodman and Armelagos 1985a). An example of this can be observed in the occlusal third of premolar crowns. Despite the fact that this portion develops during an age range known to experience high stress in many cultures (2 to 3.5 years of age), hypoplastic defects are rarely if ever observed in this region of the tooth (Goodman and Armelagos 1985a). One possible explanation for this proposed by Witzel and colleagues (2008) is that at this stage in development, ameloblasts are approaching the end of their lifespan, which is believed to not only increase their susceptibility to stress effects, but also reduces their ability to resume normal secretory activity (Witzel et al. 2008). The authors hypothesize that ameloblasts are preprogramed to secrete enamel for a finite length of time rather than a specific amount of matrix (Witzel et al. 2008). It is suggested that when ameloblasts are exposed to episodes of stress relatively late in their secretory phase, they are then unable to resume normal activity once the stress ceases (Goodman and Rose 1990). 


\section{Enamel Thickness}

A relationship has been found between the internal histology of a tooth and visible defects on its crown surface (King et al. 2005). For teeth with thicker enamel, defects at the histological level might not be as readily translated to the outer layer in comparison to those teeth with thinner enamel. In their research of enamel prisms, Marks and Rose (1985) also found that regions of the tooth crown with shorter prisms experience defects that are visible microscopically, but that are not visible on the enamel surface. This might explain the differential enamel defect distribution, especially when it is considered that incisal enamel is approximately $0.95 \mathrm{~mm}$ thick while the average enamel thickness of molars is $1.35 \mathrm{~mm}$ (Harris and Hicks 1998; Stroud et al. 1998). This theory however, fails to explain why the canine, which is one of the teeth most commonly affected by hypoplastic defects, also has a high average enamel thickness of $1.2 \mathrm{~mm}$ (Spoor et al. 1993). This finding would suggest that crown morphology alone does not account for the differential susceptibility of LEH.

\section{Enamel Deposition}

It has been proposed that the way in which enamel is deposited on the crowns of the posterior dentition is responsible for the fewer hypoplastic defects observed on them. Every tooth has some amount of appositional - or hidden - enamel on their tooth crown, which is composed of the initial layers deposited on the cusp (fig. 4). While this enamel still has striae of Retzius, the subsequent enamel layer prevents the striae from reaching the surface, and as such they do not have visible perikymata (Witzel et al. 2008). The teeth of the posterior dentition have a larger amount of appositional enamel relative to the rest of the dentition, with molars having up to $50 \%$ of their formation not readily visible (Hillson and Bond 1997). As such, any growth disruptions that occurred during their initial crown formation would be hidden and not observable on the crown surface (Hillson and Bond 1997). Additionally, the portion of enamel that is exposed on the crowns of premolars and molars is made up of perikymata grooves that are wider and shallower than those found on the crowns of the anterior teeth (King et al. 2005). Because of this, any LEH here would be less defined and more difficult to detect. These differences in the enamel of premolars and molars could result in an under representation of hypoplasia in the posterior dentition, possibly explaining the higher frequency of LEH observed in anterior teeth.

\section{Genetic Control}

\section{Differential Stability}

One of the less commonly cited theories, perhaps in part because it is less understood, is the differential genetic control experienced across the dentition. In their 1985 article, Goodman and Armelagos suggest that teeth that are more developmentally stable are more susceptible to disruptions in ameloblast activity. They argue that more mesially located teeth display higher levels of stability, a theory that is based on the increased variability observed in the size, shape, formation time, and asymmetry of the more distal teeth (Goodman and Armelagos 1985a). While the suggestion that more genetically stable teeth are more susceptible to growth disruptions might seem counter intuitive, the reasoning behind this theory is that these teeth are subsequently less flexible in their timing and size development. The authors propose that while the genetically less stable teeth of the mouth are able to respond to 
stress in different ways, such as delayed timing and reduced size, the more stable teeth can only react by temporarily stopping enamel deposition (Goodman and Armelagos 1985a). While an interesting and potentially viable theory, the amount of research into the genetic control and stability of the various tooth types is insufficient at this time.

\section{Stress Threshold}

Some authors have put forward the hypothesis that the posterior dentition has higher stress thresholds than the anterior teeth (Goodman et al. 1984; Rose et al. 1985). If this theory is correct, it would suggest that only very severe stress episodes would result in enamel defects in the premolars and molars. This could explain the lower number of posterior teeth found with $\mathrm{LEH}$, either because these levels of stressors are rare, or perhaps that they are so severe that the individual did not survive the episode long enough for there to be evidence of it on their teeth (Goodman and Rose 1990).

\section{Areas of Future Research}

\section{Deciduous Dentition}

It is apparent from a review of the current literature on LEH and hypoplasia in general that our understanding of enamel defects in the deciduous dentition is limited at best. In the majority of articles on hypoplastic primary teeth, very few note which type of defects were observed. Without this information, it is difficult if not impossible to make any inferences about the health of the sample population. While the aetiology of the various defect types is not fully understood, enough is known to discern that they are the products of different causes. Further study is also needed into the differences in the enamel of deciduous and permanent teeth, specifically how their development and composition affect their susceptibility to hypoplasia. Increasing our knowledge in this area will allow for further study into the period of human development leading up to and immediately after birth. This would also aid in our understanding of how fetal health is linked with that of the mother, expanding our ability to make inferences about the health of past populations.

\section{Genetic Influence}

Very little research has been done on how the genetic control and inherent stability of teeth factor into the formation of LEH. If the belief that various tooth types experience differential susceptibility to hypoplasia due to their varying levels of genetic influence is correct, it could drastically alter how LEH is interpreted in the archaeological record. At this time, hypoplastic defects are generally considered to be of equal severity, as there are no reliable methods with which this can be ascertained. Should this differential genetic control manifest as varying stress thresholds, research into this area could potentially provide anthropologists with the ability to distinguish between stress episodes of varying levels.

\section{Implications of LEH}

Hypoplastic defects are of interest to biological anthropologists due to the information they can provide regarding the general health of individuals and populations. Our current understanding of hypoplasia formation allows us to identify periods of stress in an individual's life, as well as to estimate the age and duration of the event. While this information alone is quite remarkable, a greater comprehension of the aetiology would allow for their interpretation in a larger context, whether that be the study of archaeological populations or the study of enamel 
defects on a modern global setting. For instance, should an individual with a high frequency of LEH be assumed to have suffered from poorer health than someone with a lower frequency? Or does this perhaps indicate that they were healthy enough to survive the stress episode, which was then recorded in their enamel as a defect. Without further research into hypoplasia, our interpretations of LEH may not be truly reflective of their full potential for information. The use of modern clinical studies may be useful in furthering our understanding of how and why $\mathrm{LEH}$ is formed.

\section{Conclusion}

While a review of the literature substantiates a differential distribution pattern of higher LEH frequencies in the anterior dentition, the explanations for these findings presented in the surveyed literature are inconclusive. It is apparent from research into the aetiology of hypoplastic defects that, similarly to the rest of the skeletal system, a multitude of factors are involved in the formation of tooth enamel. Due to these findings, it is likely that no single variable can be identified as the cause of this variation. Further study is needed to determine why the anterior teeth appear to be more susceptible to hypoplastic defects than their posterior counterparts. By assuming that all teeth have an equal hypoplastic response to stress, we are potentially misinterpreting enamel defects in relation to general health (Goodman and Armelagos 1985a). Currently, hypoplastic defects are recorded and evaluated through frequency counts, where a defect on one tooth is considered to be equal to a defect on another. However, if one of the previously outlined theories is correct in suggesting that defects on the posterior dentition are observed more rarely due to a higher stress threshold, linear enamel hypoplasia on these teeth would indicate a much greater stress episode than on the anterior dentition. In conclusion, by not fully investigating this differential susceptibility, the archaeological community may potentially be overlooking critical information in our research.

\section{References Cited}

Bartlett, J. 2013. Dental Enamel Development: Proteinases and Their Enamel Matrix Substrates. ISRN Dentistry, 2013:1-24.

Blakey, M., Leslie, T. and Reidy, J. 1994. Frequency and chronological distribution of dental enamel hypoplasia in enslaved African Americans: A test of the weaning hypothesis. American Journal of Physical Anthropology, 95(4):371-383.

Blakey, M. and Armelagos, G. 1985. Deciduous enamel defects in prehistoric Americans from Dickson Mounds: Prenatal and postnatal stress. American Journal of Physical Anthropology, 66(4):371-380.

Condon, K. 1981. Correspondence of developmental enamel defects between the mandibular canine and the first premolar. American Journal of Physical Anthropology, 54:211.

Corruccini, R., Handler, J. and Jacobi, K. 1985. Chronological Distribution of Enamel Hypoplasias and Weaning in a Caribbean Slave Population. Human Biology, 57(4):699-711.

Cucina, A. 2002. Brief communication: Diachronic investigation of linear enamel hypoplasia in prehistoric skeletal samples from Trentino, Italy. American Journal of Physical Anthropology, 119(3):283-287.

Cucina, A. and İşcan, M. 1997. Assessment of enamel hypoplasia in a high status burial site. American Journal of Human Biology, 9(2):213-222.

De Menezes Oliveira, M., Torres, C., Gomes-Silva, J., Chinelatti, M., De Menezes, F., Palma-Dibb, R. and Borsatto, M. 2009. Microstructure and mineral composition of dental enamel of permanent and deciduous teeth. Microscopy Research and Technique, 73(5):572-577.

Duray, S. 1990. Deciduous enamel defects and caries susceptibility in a prehistoric ohio population. American Journal of Physical Anthropology, 81(1):27-34.

El-Najjar, M., Desanti, M. and Ozebek, L. 1978. Prevalence and possible etiology of dental enamel hypoplasia.

American Journal of Physical Anthropology, 48(2):185192.

Goodman, A. and Armelagos, G. 1985a. Factors affecting the distribution of enamel hypoplasias within the human permanent dentition. American Journal of Physical Anthropology, 68(4):479-493. . 1985b. The chronological distribution of enamel hypoplasia in human permanent incisor and canine teeth. Archives of Oral Biology, 30(6):503-507. 
Goodman, A. and Rose, J. 1990. Assessment of systemic physiological perturbations from dental enamel hypoplasias and associated histological structures. American Journal of Physical Anthropology, 33(S11):59-110.

Gustafson, G. and Koch, G. 1974. Age estimation up to 16 years of age based on dental development. Odont Revy, 25(3):297-306.

Harris, E. and Hicks, J. 1998. A radiographic assessment of enamel thickness in human maxillary incisors. Archives of Oral Biology, 43(10):825-831.

Hillson, S. 1979. Diet and dental disease. World Archaeology, 11(2):147-162.

-1996. Dental anthropology. 1st ed. Milton Keynes UK: Lightning Source UK.

-2014. Tooth development in human evolution and bioarchaeology. 1st ed. Cambridge: Cambridge University Press.

Hillson, S. and Bond, S. 1997. Relationship of enamel hypoplasia to the pattern of tooth crown growth: A discussion. American Journal of Physical Anthropology, 104(1):89-103.

Hutchinson, D. and Larsen, C. 1988. Determination of Stress Episode Duration from Linear Enamel Hypoplasias: A Case Study from St. Catherines Island, Georgia. Human Biology, 60(1):93-110.

Infante, P. and Gillespie, G. 1974. An epidemiologic study of linear enamel hypoplasia of deciduous anterior teeth in Guatemalan children. Archives of Oral Biology, 19(11):1055-1061.

Jelliffe, D. and Jelliffe, E. 1971. Linear hypoplasia of deciduous incisor teeth in malnourished children. American Journal of Clinical Nutrition, 24(8):893.

King, T., Humphrey, L. and Hillson, S. 2005. Linear enamel hypoplasias as indicators of systemic physiological stress: Evidence from two known age-atdeath and sex populations from postmedieval London. American Journal of Physical Anthropology, 128(3):547-559.

Krenz-Niedbała, M. and Kozłowski, T. 2011. Comparing the Chronological Distribution of Enamel Hypoplasia in Rogowo, Poland (2nd century ad) Using Two Methods of Defect Timing Estimation. International Journal of Osteoarchaeology, 23(4):410-420.

Kumar, G. 2011. Orban's oral histology and embryology. 1st ed. New York: Elsevier.

Lesot, H. and Brook, A. 2009. Epithelial histogenesis during tooth development. Archives of Oral Biology, 54:S25-S33.

Liebe-Harkort, C. 2012. Cribra orbitalia, sinusitis and linear enamel hypoplasia in Swedish Roman Iron Age adults and subadults. International Journal of Osteoarchaeology, 22(4):387-397.

Liversidge, H. 2000. Crown formation times of human permanent anterior teeth. Archives of Oral Biology, 45(9):713-721.
Liversidge, H. and Molleson, T. 1999. Developing Permanent Tooth Length as an Estimate of Age. Journal of Forensic Sciences, 44(5):917-920.

Lunardelli, S. and Peres, M. 2005. Prevalence and distribution of developmental enamel defects in the primary dentition of pre-school children. Brazilian Oral Research, 19(2):144-149.

Marks, M. and Rose, J. 1985. Scanning electron microscopy of Wilson bands and enamel hypoplasias. American Journal of Physical Anthropology, 66(2):202.

Massler, M. and Schour, I. 1946. Growth of the child and the calcification pattern of the teeth. American Journal of Orthodontics and Oral Surgery, 32(9):495-517.

Moggi-Cecchi, J., Pacciani, E. and Pinto-Cisternas, J. 1994. Enamel hypoplasia and age at weaning in 19th-century Florence, Italy. American Journal of Physical Anthropology, 93(3):299-306.

Ogilvie, M., Curran, B. and Trinkaus, E. 1989. Incidence and patterning of dental enamel hypoplasia among the Neandertals. American Journal of Physical Anthropology, 79(1):25-41.

Palubeckaite, Ž., Jankauskas, R. and Boldsen, J. 2002. Enamel hypoplasia in Danish and Lithuanian Late Medieval/Early Modern samples: a possible reflection of child morbidity and mortality patterns. International Journal of Osteoarchaeology, 12(3):189-201.

Reid, D. and Ferrell, R. 2006. The relationship between number of striae of Retzius and their periodicity in imbricational enamel formation. Journal of Human Evolution, 50(2):195-202.

Ritzman, T., Baker, B. and Schwartz, G. 2008. A fine line: A comparison of methods for estimating ages of linear enamel hypoplasia formation. American Journal of Physical Anthropology, 135(3):348-361.

Rose, J., Condon, W. and Goodman, A. 1985. Diet and dentition: Developmental disturbances. In: R. Gilbert and J. Mielke, (eds.), The Analysis of Prehistoric Diets, 1st ed. Orlando, Florida: Academic Press, pp.281-306.

Scheuer, L. and Black, S. 2004. The Juvenile Skeleton. 1st ed. Academic Press.

Schour, I. and Massler, M. 1941. The development of the human dentition. Journal of the American Dental Association, 28:1153-1160.

Sciulli, P. 1977. A descriptive and comparative study of the deciduous dentition of prehistoric Ohio Valley Amerindians. American Journal of Physical Anthropology, 47(1):71-80.

Simmer, J. and Hu, J. 2001. Dental Enamel Formation and Its Impact on Clinical Dentistry. Journal of Dental Education, 65(9):896-905.

Spoor, C., Zonneveld, F. and Macho, G. 1993. Linear measurements of cortical bone and dental enamel by computed tomography: Applications and problems. American Journal of Physical Anthropology, 91(4):469484. 
Stodder, A. 1997. Subadult stress, morbidity, and longevity in Latte Period populations on Guam, Mariana Islands. American Journal of Physical Anthropology, 104(3):363-380.

Stroud, J., English, J. and Buschang, P. 1998. Enamel thickness of the posterior dentition: Its implications for nonextraction treatment. The Angle Orthodontist, 68(2):141-146.

Sunderland, E., Smith, C. and Sunderland, R. 1987. A histological study of the chronology of initial mineralization in the human deciduous dentition. Archives of Oral Biology, 32(3):167-174.

Sweeney, E., Cabrera, J., Urrutia, J. and Mata, L. 1969. Factors Associated with Linear Hypoplasia of Human Deciduous Incisors. Journal of Dental Research, 48(6):1275-1279.

Ubelaker, D. 1989. Human skeletal remains. 1st ed. Washington: Taraxacum.

Witzel, C., Kierdorf, U., Schultz, M. and Kierdorf, H. 2008. Insights from the inside: Histological analysis of abnormal enamel microstructure associated with hypoplastic enamel defects in human teeth. American Journal of Physical Anthropology, 136(4):400-414.

Wood, L. 1996. Frequency and chronological distribution of linear enamel hypoplasia in a North American colonial skeletal sample. American Journal of Physical Anthropology, 100(2):247-259.

Yamamoto, M. 1992. Secular trend of enamel hypoplasia in Japanese from the prehistoric to modern period. Journal of Palaeopathology, 2:231-238.

Zhou, L. and Corruccini, R. 1998. Enamel hypoplasias related to famine stress in living Chinese. American Journal of Human Biology, 10(6):723-733. 